\title{
Serum MMP-8 and TIMP-1 predict prognosis in colorectal cancer
}

\author{
Camilla Böckelman ${ }^{1,2^{*}}$ (D), Ines Beilmann-Lehtonen ${ }^{1}$, Tuomas Kaprio ${ }^{1,2}$, Selja Koskensalo ${ }^{1}$, Taina Tervahartiala ${ }^{3}$, \\ Harri Mustonen ${ }^{1}$, Ulf-Håkan Stenman ${ }^{4}$, Timo Sorsa ${ }^{3,5}$ and Caj Haglund ${ }^{1,2}$
}

\begin{abstract}
Background: Almost all of the extracellular matrix (ECM) components can be degraded by the endoproteinases matrix metalloproteinases (MMPs). Important regulators of MMPs, and thereby of the extracellular environment, are tissue inhibitors of metalloproteinases (TIMPs), and especially TIMP-1. Early tumor development, as well as distant metastasis, may be results of an MMP/TIMP ratio imbalance altering the ECM. MMPs are elevated in several inflammatory conditions. Our aim is to investigate the prognostic role of MMP-8, -9 , and TIMP-1 in colorectal cancer (CRC) and their relationship to inflammation.
\end{abstract}

Methods: We included 337 colorectal cancer patients and 47 controls undergoing surgery at Helsinki University Hospital in Finland, 1998-2011. Serum levels of MMP-8 and plasma levels of C-reactive protein (CRP) were determined with a timeresolved immunofluorometric assay (IFMA), and MMP-9 and TIMP-1 with commercial enzyme-linked immunosorbent assay (ELISA) kits. Association and correlation analyses were performed with the Mann-Whitney U, Kruskal-Wallis, and Spearman rank correlation tests. Survival curves were constructed according to the Kaplan-Meier method and compared with the log-rank test.

Results: Among patients with advanced disease, serum levels of MMP-8 and TIMP-1 were elevated. CRC patients with high MMP-8 (HR (hazard ratio) 1.72, 95\% confidence interval (Cl) 1.17-2.52, $P=0.005$ ) and those with high TIMP-1 (HR 1.80, 95\% Cl 1.23-2.64, $P=0.002$ ) had worse prognoses. MMP-9 level failed to serve as a prognostic factor. In multivariable survival analysis, Dukes stage, and low MMP-9/TIMP-1 molar ratio (HR 0.46, 95\% Cl 0.33-0.98, $P=0.042$ ) were independently predicted prognosis. A weak correlation between CRP and MMP-8 $\left(r_{S}=0.229, P<0.001\right)$, and TIMP-1 $\left(r_{S}=0.280, P<0.001\right)$ was noted. Among patients showing no systemic inflammatory response, MMP-8 (HR 1.66, 95\% Cl 1.10-2.53, $P=0.017)$ and TIMP-1 (HR 1.59, 95\% Cl 1.05-2.42, $P=0.029)$ were prognostic factors.

Conclusions: MMP-8 and TIMP-1 in serum, but not MMP-9, identified CRC patients with bad prognosis. Among patients showing no systemic inflammatory response, MMP-8 and TIMP-1 may associate with poor prognosis.

Keywords: Colorectal cancer, Colon cancer, MMP-8, MMP-9, TIMP-1, Prognosis, Survival

\section{Background}

Colorectal cancer (CRC), one of the most common cancers, has a high morbidity level in developed countries [1, 2]. That survival has improved may be explained by

\footnotetext{
*Correspondence: camilla.bockelman@helsinki.fi

'Department of Surgery, University of Helsinki and Helsinki University Hospital, P.O. Box 105, Haartmaninkatu 4, Terkon tutkijatilat, 3. krs, FIN-00029 HUS Helsinki, Finland

${ }^{2}$ Research Programs Unit, Translational Cancer Biology, University of Helsinki, P.O. Box 105, Haartmaninkatu 4, Terkon tutkijatilat, 3. krs, FIN-00029 HUS Helsinki, Finland

Full list of author information is available at the end of the article
}

increased screening or early awareness, as well as by improved treatment. Still, $17 \%$ of stage II and $36 \%$ of stage III patients develop a recurrence within 5 years [3]. What is of great importance is to recognize that these patients need adjuvant treatment and intensive follow-up, whereas others may be spared from laborious treatments.

Matrix metalloproteinases (MMPs) are a family of structurally related zinc-dependent endopeptidases capable of degrading almost all extraceullular matrix (ECM) components [4]. Increased MMP activity is a result of tumor cell-specific mechanisms such as angiogenesis

(c) The Author(s). 2018 Open Access This article is distributed under the terms of the Creative Commons Attribution 4.0 International License (http://creativecommons.org/licenses/by/4.0/), which permits unrestricted use, distribution, and 
and epithelial-mesenchymal transition (EMT). Additionally, MMPs can process distinct non-matrix bioactive substrates such as growth factors, complement components, pro- and anti-inflammatory cytokines, chemokines, serum proteins, and receptors. MMPs can thereby regulate immuneresponses [5, 6].

Of the 26 different MMPs recognized, several have been studied extensively in inflammatory diseases and cancer. MMP-8 and -9 belong to the collagenase subgroup of MMPs being expressed - apart from tumor cells - also by fibroblasts and infiltrating inflammatory cells [7]. In benign tissues, the ECM environment is strictly under the control, among others, of endogenous proteins called tissue inhibitors of metalloproteinases (TIMPs) [8]. TIMP-1 in particular serves by binding to MMPs as an important regulator and may inhibit the proteolytic activity of MMPs. Any imbalances in this strictly controlled process may result in altered ECM and early tumor development, and a disruption of the MMP/TIMP ratio within the microenvironment may facilitate distant metastasis [9]. TIMP-1 also exerts MMP-inhibition-independent characteristics such as growth factor-like and proinflammatory properties [10].

Elevated levels of serum MMP-8, MMP-9, and TIMP-1 have appeared in several cancers: lung, gastric, hepatocellular, and colorectal, but also in melanoma and head and neck cancer [11-17]. MMP-9 in particular has been extensively studied for its effects on tumor cell invasion and angiogenesis. The influence of elevated MMP-9 serum level on prognosis and on its ability to serve as a diagnostic maker have, however, varied [7]. MMP-8, on the other hand, has not raised as much interest, although it regulates many different proteins of the ECM [18]. High serum MMP-8 level correlates with stage, but its effect on survival was not reported there [14]. Some have shown that in colorectal cancer, preoperative plasma TIMP-1 serves as an independent prognostic marker [19], whereas others found only a limited value for TIMP-1 as a prognostic indicator [20]. According to a meta-analysis based on five different studies, colorectal cancer patients with elevated plasma or serum TIMP-1 had poorer overall survival [21]. As the balance between MMPs and TIMP-1 is tightly regulated in healthy tissues, their molar ratio may more specifically reflect the ECM environment in malignant lesions.

Colorectal cancer patients showing systemic inflammatory response have a worse prognosis [22]. In multiple other conditions linked to an activated inflammatory response, such as acute coronary syndrome, chronic urticaria, or pancreatitis, correlations exist between high MMP-9 levels and C-reactive protein (CRP) [23-25]. In colorectal cancer, high serum MMP-8 levels and high blood neutrophil and leukocyte count correlated positively [14], but correlations between TIMP-1 and white blood cell count were less clear.
The aim of our study was to investigate the prognostic roles of MMP-8, MMP-9, and TIMP-1 in colorectal cancer. Furthermore, we studied any possible relationship between elevated MMP-levels and systemic inflammatory response.

\section{Methods \\ Patients}

Of 384 patients undergoing surgery at Helsinki University Hospital, Finland, 1998-2011, 335 underwent a primary elective operation for colorectal cancer, and 47 with surgery for other reasons served as benign controls. Colorectal cancer (CRC) patients had surgery in 1998-2003 with a median follow-up time of 6.4 years (range, 1 day to 16.3 years). At the end of follow-up, 200 (59.3\%) had died. The 5-year disease-specific survival for colorectal cancer patients was $69.9 \%$ (95\% confidence interval (CI) 64.675.2), for colon cancer patients, it was $72.1 \%$ (95\% CI 64.5-79.5), and for rectal cancer patients, $67.4 \%$ (95\% CI 60.3-75.1). Of the CRC patients, 173 (51.3\%) were men, and 257 (76.3\%) had surgery with curative intent. In 156 (46.6\%) patients and the tumor was situated in the colon and in 179 (53.4\%) in the rectum; it was more frequently located in the left side of the colorectum (242; 72.2\%) (Table 1).

Median age was for the 47 controls 54.0 (interquartile range (IQR) 38.5-70.9), and 30 (64.8\%) were women. They underwent surgery for benign colorectal neoplasia (18; 38.3\%), inflammatory bowel disease $(13 ; 27.7 \%)$, or benign thyroid disease $(11 ; 23.4 \%)$, and the other 5 (10.6\%) for other reasons. Their 5-year overall survival was $90.3 \%$ (95\% CI 81.2-99.3).

\section{Serum and plasma samples}

Blood samples were obtained within 30 days prior to surgery (range 0-30 days). The majority of the samples (92.4\%) were taken within 3 days preoperatively. The samples were centrifuged, and serum and plasma components stored as aliquots at $-80{ }^{\circ} \mathrm{C}$ until analysis. The commercial MMP-9 and TIMP-1 enzyme-linked immunosorbent assay (ELISA) kits served for determination of serum levels in accordance with the manufacturer's instructions (Biotrak ELISA System; Amersham Biosciences, Buckinghamshire, UK). For MMP-9, the detection limit was $0.6 \mathrm{ng} / \mathrm{ml}$ and for TIMP-1 $1.25 \mathrm{ng} / \mathrm{ml}$ [6]. For MMP-8, we used the time-resolved immunofluorometric assay (IFMA) (Medix Biochemica, Espoo, Finland) in accordance with the manufacturer's instructions with a detection limit of $0.08 \mathrm{ng} / \mathrm{ml}[26]$.

We determined plasma CRP by a high-sensitivity method; time-resolved IFMA, with a monoclonal CRP antibody (anti-hCRP, code 6405, Medix Biochemica) as previously described [27]. 
Table 1 Characteristics of 335 colorectal cancer patients

\begin{tabular}{|c|c|}
\hline Patient characteristics & n (\%) \\
\hline \multicolumn{2}{|l|}{ Age } \\
\hline Median (IQR), years & $67.2(57.5-75.9)$ \\
\hline \multicolumn{2}{|l|}{ Gender } \\
\hline Men & $174(51.9)$ \\
\hline Women & $161(48.1)$ \\
\hline \multicolumn{2}{|l|}{ Dukes classification } \\
\hline A & 59 (17.6) \\
\hline B & $101(30.1)$ \\
\hline C & $114(34.0)$ \\
\hline $\mathrm{D}$ & $61(18.2)$ \\
\hline \multicolumn{2}{|l|}{ Tumor classification (pT) } \\
\hline pT1 & $13(3.9)$ \\
\hline pT2 & $74(22.1)$ \\
\hline pT3 & $212(63.3)$ \\
\hline pT4 & $31(9.3)$ \\
\hline \multicolumn{2}{|c|}{ Lymph node metastasis (pN) } \\
\hline pNO & $176(52.5)$ \\
\hline pN1 & $87(26.0)$ \\
\hline pN2 & $68(20.3)$ \\
\hline \multicolumn{2}{|l|}{ Distant metastasis (pM) } \\
\hline pM0 & $273(81.5)$ \\
\hline pM1 & $58(17.3)$ \\
\hline \multicolumn{2}{|l|}{ Grade (WHO) } \\
\hline 1 & $22(6.6)$ \\
\hline 2 & $31(69.0)$ \\
\hline 3 & $24(7.2)$ \\
\hline 4 & $22(6.6)$ \\
\hline \multicolumn{2}{|l|}{ Location } \\
\hline Colon & $156(46.6)$ \\
\hline Rectum & $179(53.4)$ \\
\hline \multicolumn{2}{|l|}{ Side } \\
\hline Right & $93(27.8)$ \\
\hline Left & $242(72.2)$ \\
\hline \multicolumn{2}{|l|}{ Histologic type } \\
\hline Adeno & $309(92.2)$ \\
\hline Mucinous & $26(7.8)$ \\
\hline \multicolumn{2}{|c|}{ Systemic inflammatory response } \\
\hline $\mathrm{CRP}<=30$ & $278(83.0)$ \\
\hline $\mathrm{CRP}>30$ & $51(15.2)$ \\
\hline
\end{tabular}

Abbreviation: IQR interquartile range

\section{Statistical analysis}

To determine the significance of the difference in biomarker concentrations, the Mann-Whitney U-test and Kruskal-Wallis test were applied. Correlations between the biomarkers and CRP were explored by the Spearman rank correlation test. We counted disease-specific survival from date of surgery to date of death from colorectal cancer or until end of follow-up. We used the Kaplan-Meier method to construct survival curves and compared them with the log-rank test. For biomarkers MMP-8, MMP-9, TIMP-1, MMP-8/TIMP-1, their molar ratios, and the MMP-9/TIMP-1 molar ratio were grouped as low or high according to their median values for survival analyses. For CRP, a concentration of $\leq 30$ $\mathrm{mg} / \mathrm{l}$ served as the cut-off for dichotomization. The Cox proportional hazard model served for multivariable survival analysis and we entered the following covariates: gender, age, Dukes stage, grade, histologic type, tumor location (colon vs. rectum), side (right vs. left), MMP-8, - 9, TIMP-1, and CRP serum concentration, as well as MMP/TIMP-1 molar ratios. Dukes' classification and grade, were entered as categorical covariates. Multivariable Cox regression analysis was performed according to the backward stepwise method with removal of the term at $P<0.1$. Interaction terms were considered in the final model, with no significant interactions found. The Cox proportional hazard model assumption of constant hazard ratios over time was tested by including a time-dependent variable for each testable variable separately. All variables fulfilled the assumption. We considered $P$-values of $<0.05$ statistically significant. We used the IBM SPSS Statistics version 23.0 for Mac (IBM Corporation, Armonk, NY, USA) for the statistical analyses.

\section{Results}

Of median MMP-8, MMP-9, and TIMP-1 serum levels prior to surgery for colorectal cancer and for controls with benign disease, only TIMP-1 levels were higher in patients with CRC than in controls $(P=0.037$, Mann-Whitney U-test, Table 2). No differences in molar ratios of MMP/TIMP-1 were noted between cancer patients and controls. Colorectal cancer patients had higher CRP levels than did controls $(P<0.001)$.

\section{Association of MMP-8, MMP-9, and TIMP-1 with clinicopathologic parameters}

Serum levels of MMP-8 were higher among patients with advanced disease, both in regard to locally advanced (pT4 tumors; $P=0.004$ ) and distantly metastasized disease $(P<0.001$, Table 3$)$. Serum MMP-8 was also higher among those with the tumor located in the right side of the colon $(P=0.038)$. Serum MMP-9 levels were slightly higher in men $(P=0.015)$ and in those with metastasized disease $(P=0.028)$. TIMP-1 serum levels were likewise higher among patients with locally advanced disease (pT4 tumors; $P=0.028$ ), as well as higher among patients with a right-sided tumor $(P=0.016)$. In 
Table 2 Median serum concentrations of MMP-8, MMP-9, TIMP-1, and molar ratios of MMPs and TIMP-1 in 335 colorectal cancer and 47 control patients

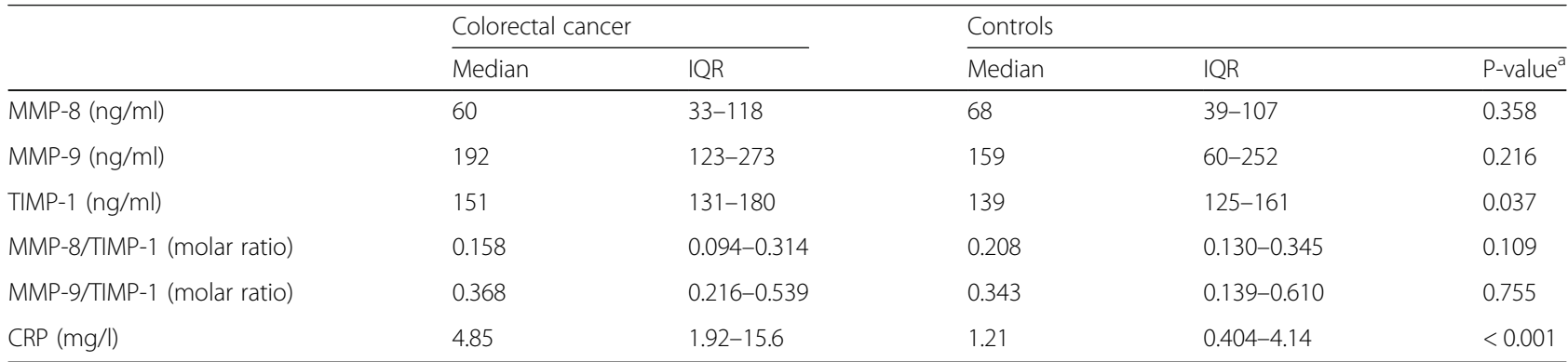

Abbreviations: MMP matrix metalloproteinase, TIMP-1 tissue inhibitor of metalloproteinases-1, CRP C-reactive protein, IQR interquartile range ${ }^{a}$ Mann-Whitney U-test

addition, serum TIMP-1 was higher among patients over $65(P<0.001)$.

The MMP-8/TIMP-1 molar ratio was as well higher among patients with metastasized disease $(P<0.001$, Additional file 1). The MMP-9/TIMP-1 molar ratio was higher among patients under $65(P=0.002)$.

We found weak positive correlations between MMP-8 and CRP $\left(\mathrm{r}_{\mathrm{S}}=0.229, p<0.001\right.$, Spearman rank correlation test), between TIMP-1 and CRP $\left(\mathrm{r}_{\mathrm{S}}=0.280, P<0.001\right)$, and between MMP-8/TIMP-1 molar ratio and CRP $\left(\mathrm{r}_{\mathrm{S}}=\right.$ $0.151, P=0.007)$. No significant correlation was noted between MMP-9 and CRP $\left(\mathrm{r}_{\mathrm{S}}=0.110, P=0.050\right)$ or MMP-9/ TIMP-1 molar ratio and CRP $\left(\mathrm{r}_{\mathrm{S}}=-0.023, P=0.678\right)$.

\section{Univariable survival analyses}

Five-year disease-specific survival according to dichotomized MMP-8, -9, and TIMP-1 concentrations and MMP/TIMP-1 molar ratios are in Additional file 2 and univariable hazard ratios in Table 4. Colorectal cancer patients with low MMP-8 levels had a 5-year survival of 76.0\% (95\% CI 69.1-82.9) and those with high MMP-8 levels 62.7\% (95\% CI 54.7-70.7; HR (hazard ratio) 1.72, 95\% CI 1.17-2.52, $P=0.005$; Fig. 1). Patients with low TIMP-1 levels had a 5-year survival of $76.4 \%$ (95\% CI 69.7-83.1) and those with high TIMP-1 levels 62.6\% (95\% CI 54.6-70.6; HR 1.80, 95\% CI 1.23-2.64, $P=0.002$ ). Patients with high MMP-8/TIMP-1 molar ratio had better survival (HR 1.48, 95\% CI 1.0-2.16, $P=0.045$ ), whereas patients with a low MMP-9/TIMP-1 molar ratio survived longer (HR 0.65, 95\% CI 0.45-0.96, $P=0.027$; Additional file 2 and Table 4). MMP-9 level did not serve as a prognostic factor.

In subgroup analyses, survival was poor for patients with high MMP-8 and colon cancer (HR 2.00, 95\% CI 1.10-3.64, $P=0.023$, Additional file 3 ), with left-sided tumor (HR 1.80, 95\% CI 1.17-2.77, $P=0.007$ ), and with no systemic inflammatory response (HR 1.66, 95\% CI 1.10-2.53, $P=0.017$, Fig. 2a-b). Low levels of MMP-9 indicated poor prognosis among rectal cancer patients (HR 0.49, 95\% CI 0.28-0.85, $P=0.011$; Additional file 3). High TIMP-1 levels indicated poor survival among patients with rectal cancer (HR 1.95, 95\% CI 1.17-3.26, $P=0.011$ ), with left-sided tumor (HR 1.95, 95\% CI 1.27-3.00, $P=0.002$ ), and with low CRP (HR $1.59,95 \%$ CI 1.05-2.42, $P=0.029$, Fig. 2c-d).

\section{Multivariable survival analysis}

We found that age, Dukes stage, and low MMP-9/ TIMP-1 molar ratio (HR 0.46, 95\% CI 0.33-0.98, $P=$ 0.042 ) served as independent prognostic factors (Table 5).

\section{Discussion}

In colorectal cancer, we found that high levels of serum MMP-8 and TIMP-1 serve as prognostic factors. Interestingly, serum MMP-9 did not influence prognosis, but low MMP-9/TIMP-1 molar ratio, together with high age and advanced Dukes stage, were each independent prognostic factors for poor prognosis. We noted that high MMP-8 and TIMP-1 associated with advanced stage and right-sided location. Among patients with normal CRP, indicating lack of systemic inflammatory response, high MMP-8 and TIMP-1 selected patients with poor prognosis.

Few studies concern the prognostic value of MMP-8, MMP-9, or TIMP-1 in colorectal cancer. In a study with 148 colorectal cancer patients, high serum MMP-8 and TIMP-1 associated with advanced stage [14]. In another, with 97 colon cancer patients, high TIMP-1 associated with shorter overall survival and emerged as an independent prognostic factor [28]. We also found an association between advanced stage (Dukes D) and high serum MMP-8 and TIMP-1. Among patients with metastasized disease, MMP-8 and TIMP-1 were more commonly elevated; their levels were higher among those with right-sided disease, which has not been previously reported. We measured MMP-9 and TIMP-1 serum levels by ELISA and MMP-8 with an IFMA method, in contrast to that of with another group, which utilized gelatin-zymography (SDS-PAGE) to detect MMP-9 levels [15]. In their 32 colorectal cancer patients, MMP-2 and MMP-9 seemed to correlate with more advanced stage; 
Table 3 Significance of the difference in MMP-8, -9, and TIMP-1 serum concentrations in 330 colorectal cancer patients

\begin{tabular}{|c|c|c|c|c|c|c|}
\hline \multirow{2}{*}{$\begin{array}{l}\text { Clinicopathological } \\
\text { variable }\end{array}$} & \multicolumn{2}{|l|}{ MMP-8 } & \multicolumn{2}{|l|}{ MMP-9 } & \multicolumn{2}{|l|}{ TIMP-1 } \\
\hline & Median (IQR) & $P$-value & Median (IQR) & $P$-value & Median (IQR) & $P$-value \\
\hline \multicolumn{7}{|l|}{$\mathrm{Age}^{\mathrm{a}}$} \\
\hline$<=65$ & $56(36-97)$ & 0.773 & $205(136-287)$ & 0.159 & $138(123-162)$ & $<0.001$ \\
\hline$>65$ & $63(32-125)$ & & $185(123-265)$ & & $164(141-196)$ & \\
\hline \multicolumn{7}{|l|}{ Gender $^{a}$} \\
\hline Male & $60(32-122)$ & 0.861 & 209 (141-299) & 0.015 & 154 (135-185) & 0.020 \\
\hline Female & $57(35-112)$ & & $183(105-254)$ & & $147(123-177)$ & \\
\hline \multicolumn{7}{|l|}{ Dukes classification ${ }^{b}$} \\
\hline A & $50(31-76)$ & $<0.001$ & $171(95-269)$ & 0.040 & $142(122-163)$ & 0.024 \\
\hline B & 55 (33-90) & & $194(131-318)$ & & 153 (131-183) & \\
\hline C & $51(30-101)$ & & $183(123-246)$ & & $152(134-178)$ & \\
\hline D & $137(56-328)$ & & $223(161-310)$ & & $166(132-257)$ & \\
\hline \multicolumn{7}{|l|}{$\mathrm{pT}^{\mathrm{b}}$} \\
\hline pT1 & $50(22-64)$ & 0.004 & $237(83-297)$ & 0.113 & 144 (117-190) & 0.028 \\
\hline pT2 & $50(27-90)$ & & $164(101-244)$ & & $144(126-166)$ & \\
\hline pT3 & $58(34-129)$ & & $195(128-287)$ & & $152(131-179)$ & \\
\hline pT4 & $93(58-265)$ & & $211(165-284)$ & & $180(148-244)$ & \\
\hline \multicolumn{7}{|l|}{$\mathrm{pN}^{\mathrm{b}}$} \\
\hline pNO & 56 (33-93) & 0.238 & $148(127-175)$ & 0.183 & 149 (127) & 0.372 \\
\hline pN1 & 64 (33-93) & & $154(135-181)$ & & $154(135-181)$ & \\
\hline $\mathrm{pN} 2$ & $63(35-140)$ & & $160(130-188)$ & & 160 (130-188) & \\
\hline \multicolumn{7}{|l|}{$\mathrm{pM}^{\mathrm{a}}$} \\
\hline $\mathrm{pMO}$ & $54(32-94)$ & $<0.001$ & $189(121-265)$ & 0.028 & $150(131-175)$ & 0.054 \\
\hline $\mathrm{pM} 1$ & $118(56-332)$ & & $221(159-304)$ & & $165(131-259)$ & \\
\hline \multicolumn{7}{|l|}{ Grade $(\mathrm{WHO})^{\mathrm{b}}$} \\
\hline 1 & $66(34-173)$ & 0.227 & $204(137-293)$ & 0.717 & 166 (110-197) & 0.727 \\
\hline 2 & $60(33-113)$ & & $193(116-273)$ & & $150(131-179)$ & \\
\hline 3 & $41(27-78)$ & & 159 (136-299) & & 163 (137-182) & \\
\hline 4 & $102(36-185)$ & & $215(183-273)$ & & 157 (126-189) & \\
\hline \multicolumn{7}{|l|}{ Location $^{a}$} \\
\hline Colon & 65 (35-134) & 0.104 & $204(143-284)$ & 0.116 & $157(131-187)$ & 0.053 \\
\hline Rectum & $54(32-103)$ & & 185 (109-273) & & $148(131-174)$ & \\
\hline \multicolumn{7}{|l|}{ Side $e^{a}$} \\
\hline Right & $70(39-134)$ & 0.038 & $208(152-290)$ & 0.266 & 161 (135 (191) & 0.016 \\
\hline Left & $54(32-104)$ & & $189(120-273)$ & & $149(130-175)$ & \\
\hline \multicolumn{7}{|l|}{ Histologic type ${ }^{a}$} \\
\hline Adeno & $58(33-120)$ & 0.726 & $192(125-274)$ & 0.374 & $152(131-182)$ & 0.558 \\
\hline Mucinous & $63(40-96)$ & & $221(157-320)$ & & 156 (126-198) & \\
\hline
\end{tabular}

Abbreviations: MMP matrix metalloproteinase, TIMP-1 tissue inhibitor of matrix metalloproteinase-1, IQR interquartile range ${ }^{\mathrm{a}}$ Mann-Whitney U-test, ${ }^{\text {b }}$ Kruskal-Wallis test

however, by this method, their results may be, at least in part, uncertain [15]. Gelatin-zymography assaying semiquantitatively SDS-treated catalytic activities of MMP-2 and -9 does not analyze the concentrations of MMP-2 and -9 as precisely as do IFMA and ELISA utilizing highly specific antibodies [29]. Their conclusion that MMP-9 would serve as an independent prognostic marker cannot be drawn based on their results. All in all, MMP-8 and TIMP-1 seem to influence the prognosis of colorectal cancer patients to a greater extent than MMP-9 seems to do. 
Table 4 Univariable Cox regression analysis of disease-specific survival for colorectal cancer patients

\begin{tabular}{|c|c|c|c|}
\hline & Hazard ratio & $95 \% \mathrm{Cl}$ & $P$-value \\
\hline \multicolumn{4}{|l|}{ Age, years } \\
\hline$<=65$ & 1.00 & & \\
\hline$>65$ & 1.44 & $0.98-2.10$ & 0.062 \\
\hline \multicolumn{4}{|l|}{ Gender } \\
\hline Male & 1.00 & & \\
\hline Female & 1.06 & $0.73-1.54$ & 0.772 \\
\hline \multicolumn{4}{|c|}{ Dukes classification } \\
\hline$A$ & 1.00 & & \\
\hline$B$ & 3.33 & $0.96-11.5$ & 0.057 \\
\hline C & 11.0 & $3.45-35.3$ & $<0.001$ \\
\hline$D$ & 29.3 & $9.05-95.1$ & $<0.001$ \\
\hline \multicolumn{4}{|l|}{ pT stage } \\
\hline pT1 & 1.00 & & \\
\hline pT2 & 1.62 & $0.21-12.8$ & 0.648 \\
\hline pT3 & 6.33 & $0.88-45.5$ & 0.067 \\
\hline pT4 & 9.89 & $1.31-75.0$ & 0.067 \\
\hline \multicolumn{4}{|l|}{ pN stage } \\
\hline pNO & 1.00 & & \\
\hline pN1 & 3.77 & $2.33-6.09$ & $<0.001$ \\
\hline $\mathrm{pN} 2$ & 5.16 & $3.15-8.50$ & $<0.001$ \\
\hline \multicolumn{4}{|l|}{ pM stage } \\
\hline $\mathrm{pMO}$ & 1.00 & & \\
\hline pM1 & 5.31 & $3.55-7.93$ & $<0.001$ \\
\hline \multicolumn{4}{|l|}{ Grade } \\
\hline । & 1.00 & & \\
\hline$\|$ & 1.38 & $0.60-3.17$ & 0.445 \\
\hline III & 1.07 & $0.36-3.18$ & 0.906 \\
\hline IV & 2.16 & $0.78-5.93$ & 0.137 \\
\hline \multicolumn{4}{|l|}{ Side } \\
\hline Right & 1.00 & & \\
\hline Left & 1.45 & $0.92-2.28$ & 0.107 \\
\hline \multicolumn{4}{|l|}{ Location } \\
\hline Colon & 1.00 & & \\
\hline Rectum & 1.16 & $0.79-1.69$ & 0.453 \\
\hline \multicolumn{4}{|c|}{ Histologic type } \\
\hline Adeno & 1.00 & & \\
\hline Mucinous & 0.95 & $0.46-1.95$ & 0.888 \\
\hline \multicolumn{4}{|c|}{ MMP-8 concentration } \\
\hline Low & 1.00 & & \\
\hline High & 1.72 & $1.17-2.52$ & 0.005 \\
\hline \multicolumn{4}{|c|}{ MMP-9 concentration } \\
\hline Low & 1.00 & & \\
\hline High & 0.89 & $0.61-1.31$ & 0.564 \\
\hline
\end{tabular}

Table 4 Univariable Cox regression analysis of disease-specific survival for colorectal cancer patients (Continued)

\begin{tabular}{llll}
\hline & Hazard ratio & $95 \% \mathrm{Cl}$ & P-value \\
\hline $\begin{array}{l}\text { TIMP-1 concentration } \\
\text { Low }\end{array}$ & 1.00 & & \\
High & 1.80 & $1.23-2.64$ & 0.002 \\
MMP-8/TIMP-1 ratio & & & \\
Low & 1.00 & & \\
High & 1.48 & $1.01-2.16$ & 0.045 \\
MMP-9/TIMP-1 ratio & & & \\
Low & 1.00 & & \\
High & 0.65 & $0.45-0.96$ & 0.027 \\
CRP (mg/l) & & & \\
$<=30$ & 1.00 & $1.09-2.82$ & 0.021 \\
$>30$ & 1.75 & & \\
\hline
\end{tabular}

Abbreviations: MMP matrix metalloproteinase, TIMP-1 tissue inhibitor of metalloproteinases-1, $\mathrm{Cl}$ confidence interval

In hepatocellular carcinoma, high levels of MMP-8 and TIMP-1 have indicated poor survival, as did our levels in CRC [13]. We found in CRC that although MMP-9 levels had no influence on survival, patients with a low MMP-9/TIMP-1 ratio had impaired survival, in line with their results in hepatocellular carcinoma. Similar findings have appeared also in patients with malignant melanoma, for whom high TIMP-1 indicated impaired disease-free survival [16], and in head and neck squamous cell carcinoma patients who had shorter disease-free survival [17].

Prognosis is worse for patients with right-sided colorectal (RCC) than with left-sided colorectal cancer (LCC) [30]. Right-sided tumors more frequently are microsatellite instable and, express KRAS and BRAF mutations, whereas LCC patients more frequently have mutations in p53, NRAS, and show chromosomal instability (CIN) which may imply a different genetic background [31, 32]. Moreover, patients with RCC microsatellite stable tumors have a significantly worse prognosis than those that have microsatellite instable tumors [31]. Although MMP-8 and TIMP-1 expression more frequently was higher in patients with right-sided tumors, MMP-8 and TIMP-1 did not serve as prognostic factors among these subgroups. On the contrary, we found that high MMP-8 served as a prognostic factor in the subgroup of colon cancer and patients with tumors located on the left side of the colorectum.

Among colon cancer patients, especially within those with left-sided disease, MMP-8 served as a prognostic factor. In rectal cancer, high MMP-9 and high TIMP-1 served as prognostic factors. In addition, high TIMP-1 was an indicator of poor prognosis among patients with 


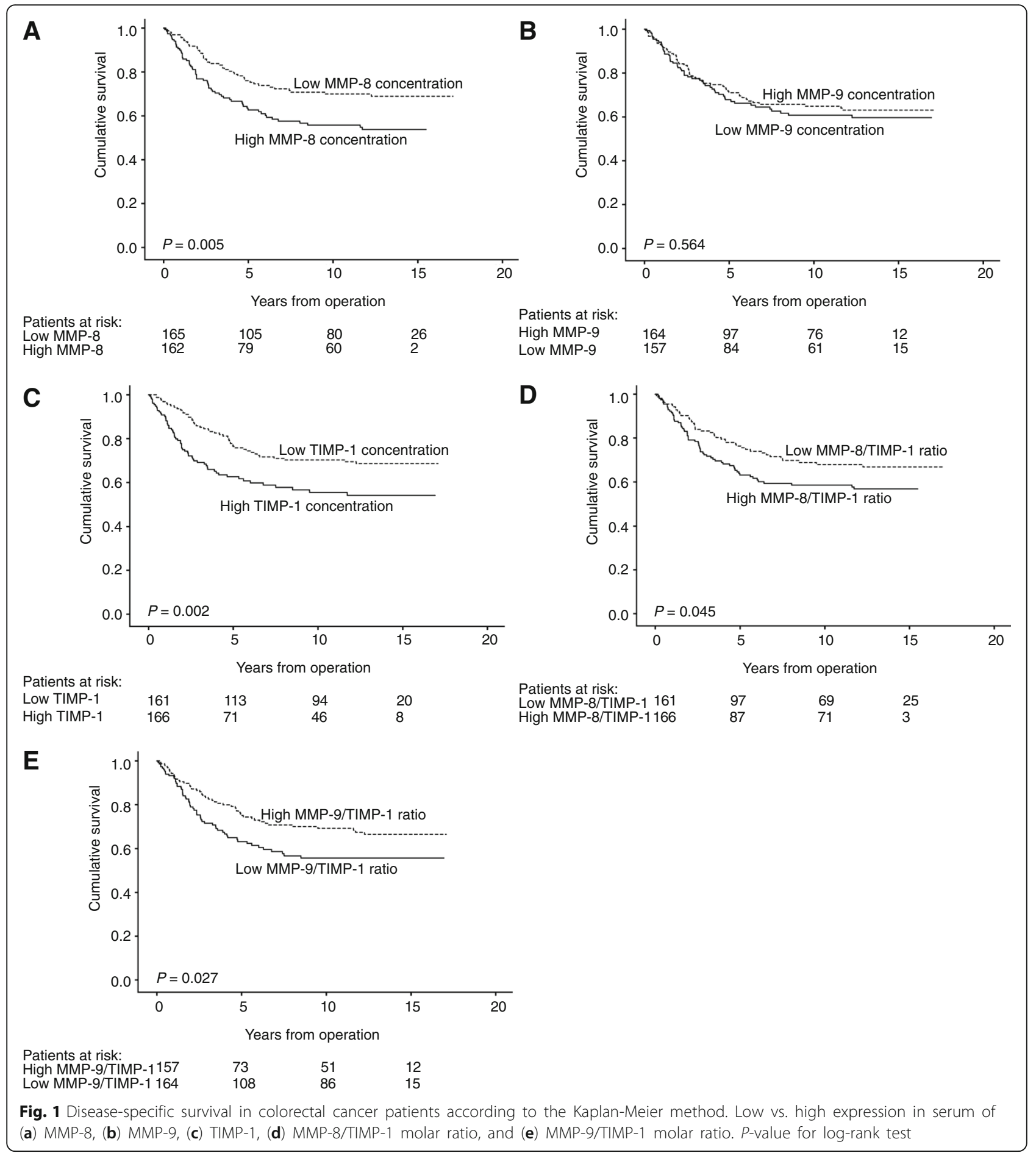

left-sided disease. These acknowledged differences in genetic background explain why MMP expression influences prognosis in different ways. Instead of the two-sided colon model - where right and left are divided at the splenic flexure - a shift towards a multisegmental model displaying a continual shift in protein expression may eventually better serve as a model [32].
CRP is a marker of systemic inflammation, with a convincing prognostic influence in colorectal cancer [22, 33]. As on one hand, TIMP-1 has a growth factor-like role directly affecting cancer cell growth, invasion, and migration independent of TIMP:s inhibition of MMPs $[9,10]$, and on the other hand, both MMPs and TIMP-1 play an important role in inflammatory processes, we 


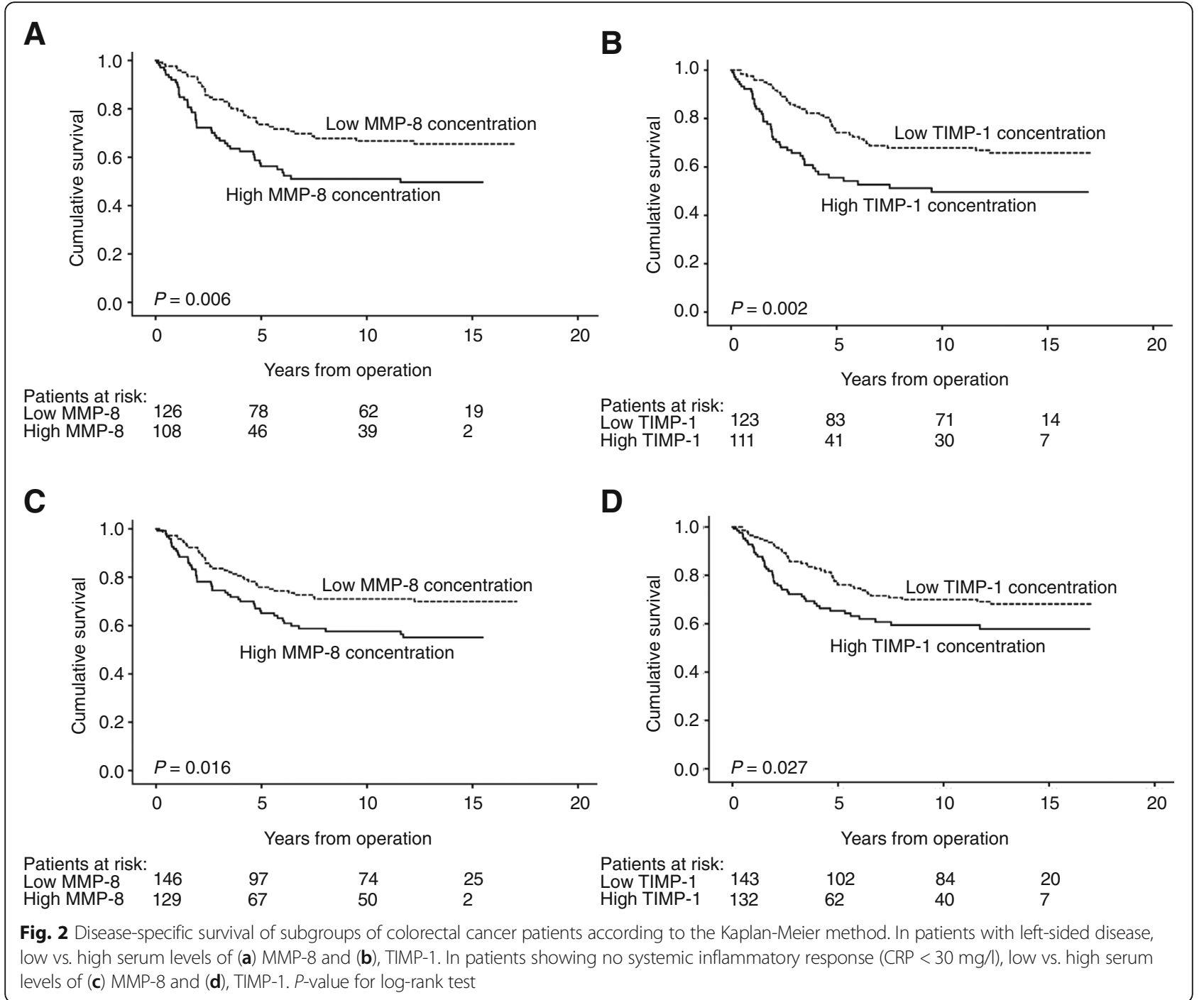

explored whether MMPs and CRP correlate. We found a weak positive correlation between MMP-8 and CRP levels, as well as between TIMP-1 and CRP. In patients with low CRP, high MMP-8 and TIMP-1 were prognostic factors independent of CRP, whereas among patients with high CRP reflecting a systemic inflammation response, MMPs or TIMP-1 failed to select those patients with a worse prognosis. In acute coronary syndrome, MMP and CRP are correlated, and CRP seems to induce local MMP-9 secretion [25]. In chronic urticaria, on the other hand, high levels of MMP-9 and CRP are related to disease severity [23]. Oral cancer patients with high MMP-9 and CRP levels have had worse prognosis [34].

Few studies have reported on the relation between MMP and CRP in CRC. During adenoma-carcinoma development, a progressive increase in interleukin-8 (IL-8), CRP, and MMP-9 occurs. Among 26 stage III colorectal cancer patients, levels of MMP-9 and IL-8 were significantly elevated and correlated with each other [35].
Likewise, MMP-8 correlates with high leukocyte and neutrophil count, whereas TIMP-1 correlates only weakly with neutrophil count [14]. Among 525 colon cancer cases, patients with high CRP had poor prognosis, a result that was sustained within all disease stages when analyzed separately [22]. Kostner et al. [33] demonstrated that even among CRC patients with metastatic disease, high CRP serves as a prognostic marker. MMP-8 is produced mainly by neutrophils and reflects a response in the acute phase of inflammation [5, 36]. Conversely, MMP-9 is produced by several different cell types, so its serum levels are more easily affected and any correlation with stage or prognosis may thus be diluted [4].

We found that, compared with levels in healthy controls, only TIMP-1 levels were marginally elevated among the cancer patients. In contrast, in a study on 180 patients, of whom 75 had colorectal cancer, MMP-9 and TIMP-1 levels were higher in colorectal cancer patients than in healthy controls or in colorectal adenoma patients [37]. In that 
Table 5 Multivariable Cox regression analysis of disease-specific survival for colorectal cancer patients

\begin{tabular}{llll}
\hline & Hazard ratio & $95 \% \mathrm{Cl}$ & $P$-value \\
\hline $\begin{array}{lll}\text { Age, years } \\
<=65\end{array}$ & 1.00 & & \\
$>65$ & 1.86 & $1.14-3.03$ & 0.013 \\
$\begin{array}{c}\text { Dukes classification } \\
\text { A }\end{array}$ & & \\
B & 1.00 & & \\
C & 1.87 & $0.504-6.93$ & 0.350 \\
D & 8.63 & $2.64-28.2$ & $<0.001$ \\
& 15.1 & $4.43-51.6$ & $<0.001$
\end{tabular}

MMP-8/TIMP-1 ratio

$$
\begin{array}{ll}
\text { Low } & 1.00 \\
\text { High } & 1.72
\end{array}
$$

$0.979-3.02$

MMP-9/TIMP-1 ratio

\begin{tabular}{llll} 
Low & 1.00 & & \\
High & 0.573 & $0.335-0.980$ & 0.042 \\
\hline
\end{tabular}

Abbreviations: MMP matrix metalloproteinase, TIMP-1 tissue inhibitor of metalloproteinases-1, $\mathrm{Cl}$ confidence interval

study, MMP-9 and TIMP-1 also correlated with tumor stage, but no data were presented on survival nor, in contrast with our results, did patients with colon cancer have higher levels of MMP-9 than did rectal cancer patients. Our primary aim was to study the prognostic role of MMP-8, - 9, and TIMP-1, and thus, benign control patients could be few.

We investigated optimal cut-offs by the aid of receiver-operating curves (ROC) and found them to be close to median values. Therefore, we chose to dichotomize our variables according to median values. Unfortunately, it was impossible to study the correlation between serum and tissue expression of MMP- 8 and -9 , because the previous tissue results were from an earlier series studied at our institution [38]. In that series, we found that MMP-9 served as a prognostic marker among Dukes B patients. However, protein serum and tissue expression does not necessarily correlate; local expression in tissue may reflect intact cells and glands, and hence only small amounts of the protein are released into the circulation.

\section{Conclusions}

Serum MMP-8 and TIMP-1 may serve as prognostic factors in colorectal cancer. Among patients showing no systemic inflammatory response, high MMP-8 and TIMP-1 may associate with poor prognosis.

\section{Additional files}

Additional file 1: Significance of the difference in MMP-8/TIMP-1 and MMP-9/TIMP-1 molar ratios in 330 colorectal cancer patients. (PDF $27 \mathrm{~kb}$ )
Additional file 2: 5 -year disease-specific survival with 95\% confidence intervals for MMP-8, -9 , and TIMP-1 in colorectal cancer patients. (PDF $20 \mathrm{~kb}$ )

Additional file 3: Univariable Cox regression analyses for subgroups for disease-specific survival in colorectal cancer patients. (PDF 19 kb)

\section{Abbreviations}

Cl: Confidence interval; CIN: Chromosomal instability; CRC: Colorectal cancer; CRP: C-reactive protein; ELISA: Enzyme-linked immunosorbent assay; HR: Hazard ratio; IFMA: Immunofluorometric assay; IL-8: Interleukin-8; IQR: Interquartile range; LCC: Left-sided colorectal cancer; MMP: Matrix metalloproteinase; RCC: Right-sided colorectal cancer; SDS-PAGE: Sodium dodecyl sulfate-polyacrymid gel; TIMP-1: Tissue inhibitor of metalloproteinases-1

\section{Acknowledgments}

We thank Elina Aspiala for excellent technical assistance.

\section{Prior publication}

Preliminary results of this work have been presented as a poster at the 19th World Congress on Gastrointestinal Cancer in Barcelona, Spain, on 28th June 2017 by C. Böckelman [39].

\section{Funding}

This study was financially supported by the Competitive State Research Financing of the Expert Responsibility Area of Turku University Hospital and Vaasa Central Hospital (CB) and Helsinki University Hospital $(\mathrm{CH})$, the Finnish Cancer Foundation ( $\mathrm{CH}, \mathrm{TK})$, the Helsinki University Central Hospital Research Foundation (TS), Karolinska Institutet, Stockholm, Sweden (TS), and the Sigrid Juselius Foundation $(\mathrm{CH})$. The funders had no role in the design of the study, analysis, interpretation of data, nor in writing the manuscript.

\section{Availability of data and materials}

The datasets analyzed during the current study are available from the corresponding author on reasonable request.

\section{Authors' contributions}

$\mathrm{CB}$, TS, and $\mathrm{CH}$ were responsible for the conception and study design. $\mathrm{CB}$, $I B L, T K$, and SK collected and processed the data. CB, TT, HM, TS, UHS, and $\mathrm{CH}$ analyzed and interpreted data. $\mathrm{CB}$ and IBL drafted the manuscript. All authors have agreed to the content of, revised, and given final approval to the current version of the manuscript.

\section{Ethics approval and consent to participate}

The Surgical Ethics Committee of Helsinki University Hospital (Dnro HUS 226/ E6/06, extension TMKO2 $\$ 66$ 17.4.2013) and the National Supervisory Authority of Welfare and Health (Valvira Dnro 10,041/06.01.03.01/2012) approved the study. Helsinki University Hospital approved our retrospective collection of data and specimens (Dnro HUS 269/2017). For this type of retrospective study, written consent from participants is according to the Finnish law not required. The approval to conduct the retrospective study without individual informed consent came from the National Supervisory Authority of Welfare and Health (Valvira Dnro 10,041/06.01.03.01/2012) and is supported by the following Finnish laws: Act on the Medical Use of Human Organs, Tissues and Cells (No. 101/2001: §20 (1), §22 (2), and §23, and No. 594/2001: §12 and §13).

Consent for publication

Not applicable.

\section{Competing interests}

The authors declare that they have no competing interests.

\section{Publisher's Note}

Springer Nature remains neutral with regard to jurisdictional claims in published maps and institutional affiliations.

\section{Author details}

${ }^{1}$ Department of Surgery, University of Helsinki and Helsinki University Hospital, P.O. Box 105, Haartmaninkatu 4, Terkon tutkijatilat, 3. krs, FIN-00029 
HUS Helsinki, Finland. ${ }^{2}$ Research Programs Unit, Translational Cancer Biology, University of Helsinki, P.O. Box 105, Haartmaninkatu 4, Terkon tutkijatilat, 3. krs, FIN-00029 HUS Helsinki, Finland. ${ }^{3}$ Department of Oral and Maxillofacial Diseases, Helsinki University Hospital and Biomedicum Helsinki, P.O. Box 63, Haartmaninkatu 8, 2nd floor, FIN-00014 Helsinki, Finland. ${ }^{4}$ Department of Clinical Chemistry, University of Helsinki and Helsinki University Hospital, P.O. Box 700, FIN-00029 HUS Helsinki, Finland. ${ }^{5}$ Department of Dental Medicine, Karolinska Institutet, Huddinge, Sweden.

Received: 29 May 2017 Accepted: 13 June 2018

\section{Published online: 22 June 2018}

\section{References}

1. Torre LA, Bray F, Siegel RL, Ferlay J, Lortet-Tieulent J, Jemal A. Global cancer statistics, 2012. CA Cancer J Clin. 2015;65:87-108.

2. Siegel RL, Miller KD, Jemal A. Cancer statistics, 2015. CA Cancer J Clin. 2015;65:5-29.

3. Böckelman C, Engelmann BE, Kaprio T, Hansen TF, Glimelius B. Risk of recurrence in patients with colon cancer stage II and III: a systematic review and meta-analysis of recent literature. Acta Oncol. 2015;54:5-16.

4. Egeblad M, Werb Z. New functions for the matrix metalloproteinases in cancer progression. Nat Rev Cancer. 2002;2:161-74.

5. Sorsa T, Tjäderhane L, Konttinen $\mathrm{YT}$, Lauhio A, Salo T, Lee H-M, et al. Matrix metalloproteinases: contribution to pathogenesis, diagnosis and treatment of periodontal inflammation. Ann Med. 2006;38:306-21.

6. Lauhio A, Färkkilä E, Pietiläinen KH, Åström P, Winkelmann A, Tervahartiala T, et al. Association of MMP-8 with obesity, smoking and insulin resistance. Eur J Clin Investig. 2016;46:757-65.

7. Herszenyi L, Hritz I, Lakatos G, Varga MZ, Tulassay Z. The behavior of matrix metalloproteinases and their inhibitors in colorectal cancer. Int J Mol Sci. 2012;13:13240-63.

8. Chirco R, Liu X-W, Jung K-K, Kim H-RC. Novel functions of TIMPs in cell signaling. Cancer Metastasis Rev. 2006;25:99-113.

9. Bourboulia D, Stetler-Stevenson WG. Matrix metalloproteinases (MMPs) and tissue inhibitors of metalloproteinases (TIMPs): positive and negative regulators in tumor cell adhesion. Semin Cancer Biol. 2010;20:161-8.

10. Jackson HW, Defamie V, Waterhouse P, Khokha RTIMP. versatile extracellular regulators in cancer. Nat Rev Cancer. 2017;17:38-53.

11. Hoikkala S, Paakko P, Soini Y, Makitaro R, Kinnula V, Turpeenniemi-Hujanen T. Tissue MMP-2 and MMP-9 [corrected] are better prognostic factors than serum MMP-2/TIMP-2-complex or TIMP-1 [corrected] in stage [corrected] IIII lung carcinoma. Cancer Lett. 2006;236:125-32.

12. Endo K, Maehara Y, Baba H, Yamamoto M, Tomisaki S, Watanabe A, et al. Elevated levels of serum and plasma metalloproteinases in patients with gastric cancer. Anticancer Res. 1997;17:2253-8.

13. Lempinen M, Lyytinen I, Nordin A, Tervahartiala T, Makisalo H, Sorsa T, et al. Prognostic value of serum MMP-8, -9 and TIMP-1 in patients with hepatocellular carcinoma. Ann Med. 2013:45:482-7.

14. Vayrynen JP, Vornanen J, Tervahartiala T, Sorsa T, Bloigu R, Salo T, et al. Serum MMP-8 levels increase in colorectal cancer and correlate with disease course and inflammatory properties of primary tumors. Int J Cancer. 2012; 131:E463-74.

15. Dragutinovic W, Radonjic NV, Petronijevic ND, Tatic SB, Dimitrijevic IB, Radovanovic NS, et al. Matrix metalloproteinase-2 (MMP-2) and -9 (MMP-9) in preoperative serum as independent prognostic markers in patients with colorectal cancer. Mol Cell Biochem. 2011;355:173-8.

16. Lugowska I, Kowalska M, Fuksiewicz M, Kotowicz B, Mierzejewska E, KosełaPaterczyk $H$, et al. Serum markers in early-stage and locally advanced melanoma. Tumour Biol. 2015;36:8277-85.

17. Ruokolainen $\mathrm{H}$, Paakko $\mathrm{P}$, Turpeenniemi-Hujanen $\mathrm{T}$. Tissue inhibitor of matrix metalloproteinase-1 is prognostic in head and neck squamous cell carcinoma: comparison of the circulating and tissue immunoreactive protein. Clin Cancer Res. 2005;11:3257-64.

18. Lopez-Otin C, Palavalli LH, Samuels Y. Protective roles of matrix metalloproteinases: from mouse models to human cancer. Cell Cycle. 2009; 8:3657-62.

19. Birgisson H, Nielsen HJ, Christensen IJ, Glimelius B, Brunner N. Preoperative plasma TIMP-1 is an independent prognostic indicator in patients with primary colorectal cancer: a prospective validation study. Eur J Cancer. 2010; 46:3323-31.
20. Oberg A, Hoyhtya M, Tavelin B, Stenling R, Lindmark G. Limited value of preoperative serum analyses of matrix metalloproteinases (MMP-2, MMP-9) and tissue inhibitors of matrix metalloproteinases (TIMP-1, TIMP-2) in colorectal cancer. Anticancer Res. 2000;20:1085-91.

21. Lee J-H, Choi J-W, Kim Y-S. Plasma or serum TIMP-1 is a predictor of survival outcomes in colorectal cancer: a meta-analysis. J Gastrointestin Liver Dis. 2011;20:287-91.

22. Kersten C, Louhimo J, Algars A, Lahdesmaki A, Cvancerova M, Stenstedt K, et al. Increased C-reactive protein implies a poorer stage-specific prognosis in colon cancer. Acta Oncol. 2013;52:1691-8.

23. Tedeschi A, Asero R, Lorini M, Marzano AV, Cugno M. Plasma levels of matrix metalloproteinase-9 in chronic urticaria patients correlate with disease severity and $\mathrm{C}$-reactive protein but not with circulating histaminereleasing factors. Clin Exp Allergy. 2010;40:875-81.

24. Chen P, Yuan Y, Wang S, Zhan L, Xu J. Serum matrix metalloproteinase 9 as a marker for the assessment of severe acute pancreatitis. Tohoku J Exp Med. 2006;208:261-6.

25. Cimmino G, Ragni M, Cirillo P, Petrillo G, Loffredo F, Chiariello M, et al. Creactive protein induces expression of matrix metalloproteinase-9: a possible link between inflammation and plaque rupture. Int J Cardiol. 2013; 168:981-6.

26. Tuomainen AM, Nyyssonen K, Laukkanen JA, Tervahartiala T, Tuomainen T-P, Salonen JT, et al. Serum matrix metalloproteinase-8 concentrations are associated with cardiovascular outcome in men. Arterioscler Thromb Vasc Biol. 2007;27:2722-8.

27. Salmiheimo A, Mustonen $H$, Stenman U-H, Puolakkainen P, Kemppainen E, Seppanen $\mathrm{H}$, et al. Systemic inflammatory response and elevated tumour markers predict worse survival in Resectable pancreatic ductal adenocarcinoma. PLoS One. 2016;11:e0163064.

28. Giaginis C, Nikiteas N, Margeli A, Tzanakis N, Rallis G, Kouraklis G, et al. Serum tissue inhibitor of metalloproteinase 1 and 2 (TIMP-1 and TIMP-2) levels in colorectal cancer patients: associations with clinicopathological variables and patient survival. Int J Biol Markers. 2009;24:245-52.

29. Hotakainen K, Ljungberg B, Paju A, Rasmuson T, Alfthan H, Stenman U-H. The free $\beta$-subunit of human chorionic gonadotropin as a prognostic factor in renal cell carcinoma. Br J Cancer. 2002;86:185-9.

30. Petrelli F, Tomasello G, Borgonovo K, Ghidini M, Turati L, Dallera P, et al. Prognostic survival associated with left-sided vs right-sided Colon Cancer: a systematic review and meta-analysis. JAMA Oncol. 2016;3:211-9.

31. Shen H, Yang J, Huang Q, Jiang M-J, Tan Y-N, Fu J-F, et al. Different treatment strategies and molecular features between right-sided and leftsided colon cancers. World J Gastroenterol. 2015;21:6470-8.

32. Yamauchi M, Lochhead P, Morikawa T, Huttenhower C, Chan AT, Giovannucci E, et al. Colorectal cancer: a tale of two sides or a continuum? Gut. 2012;61:794-7.

33. Kostner AH, Kersten C, Lowenmark T, Ydsten KA, Peltonen R, Isoniemi $H$, et al. The prognostic role of systemic inflammation in patients undergoing resection of colorectal liver metastases: C-reactive protein (CRP) is a strong negative prognostic biomarker. J Surg Oncol. 2016;114:895-9.

34. Chang P-Y, Kuo Y-B, Wu T-L, Liao C-T, Sun Y-C, Yen T-C, et al. Association and prognostic value of serum inflammation markers in patients with leukoplakia and oral cavity cancer. Clin Chem Lab Med. 2013;51:1291-300.

35. Biasi F, Guina T, Maina M, Nano M, Falcone A, Aroasio E, et al. Progressive increase of matrix metalloprotease-9 and interleukin-8 serum levels during carcinogenic process in human colorectal tract. PLoS One. 2012;7:e41839.

36. Van Lint P, Libert C. Matrix metalloproteinase-8: cleavage can be decisive. Cytokine Growth Factor Rev. 2006;17:217-23.

37. Mroczko B, Groblewska M, Okulczyk B, Kedra B, Szmitkowski M. The diagnostic value of matrix metalloproteinase 9 (MMP-9) and tissue inhibitor of matrix metalloproteinases 1 (TIMP-1) determination in the sera of colorectal adenoma and cancer patients. Int J Color Dis. 2010:25:1177-84.

38. Koskensalo S, Hagström J, Linder N, Lundin M, Sorsa T, Louhimo J, et al. Lack of MMP-9 expression is a marker for poor prognosis in dukes' B colorectal cancer. BMC Clin Pathol. 2012;12:24.

39. Böckelman C, Beilmann-Lehtonen I, Kaprio T, Koskensalo S, Tervahartiala T, Hagström J, et al. Prognostic significance of serum MMP-8, -9, and TIMP-1 in colorectal cancer. Ann Oncol. 2017;28(suppl_3):iii1-iii12. https://doi.org/ 10.1093/annonc/mdx263. 